\title{
Diagnóstico Diferencial de Síndromes de Hipoplasia Medular Asociada a Malformación de Extremidades
}

\author{
Bianca Curotto L.; M. Angélica Alliende R. o Yves Lacassic S. ${ }^{(1)}$
}

\author{
Current Differential Diagnosis of Syndromes of Bone \\ Marrow Hypoplasia Associnted to Limb Malformation
}

\begin{abstract}
We describe two sibs with typical Fanconi Pancytopenia (F.A.); a newborn with Trombocy topenia and Absent Radius (T.A.R.) who died soon atter birth, and an infant with absent radii and thumbs and transient trombocytopenia present at birth. In this patjent the finding of $10 \%$ of mitosis with chromosomal fractures and gaps would establish an unusually carly diagnosis of $\mathbf{F}$. A.

The current knowledge about F.A., T.A.R. and Aase syndrome as well the differential diagnosis between these syndromes of marrow hypoplasiz assocjated to limbs malformations are reviewed. The basic clues for the diagnosis of these uncommon disorders are stressed.
\end{abstract}

En la actualidad existen tres síndromes en que se asocia disfunción medular con malformación de extremidades, específicamente defectos radiales. Estos sindromes son la Pancitopenia o Anemia de Fanconi (AF), el Sindrome de Trombocitopenia con Ausencia de Radios (TAR) y el Sindrome de Aase. El establecer un diagnóstico preciso entre estos síndromes, además de tener importancia para el consejo genético, es fundamental para establecer el pronóstico y expectativas de vida de estos pacientes.

Anemia de Fanconi: Este síndrome fue descrito por Fanconi en 1927, en 3 hermanos $(5,6$ y 7 años), en los que se encontró fallas en la médula ósea asociada a múltiples malformaciones congénitas (1). Las manifestaciones más importantes de la AF son pancitopenia, retraso del crecimiento, pigmentación de la piel, defectos congénitos, especialmente del pulgar $y$ radio y malformaciones renales. Microcefalia, hipogenitalismo, retraso mental y múltiples otras alteraciones son menos frecuentes $(2,3)$.

\footnotetext{
1 Unidad de Genética, Insticuto de Nutrición y Tecnología de los Alimentos, Universidad de Chile.
}

Schroeder et al., en 1964, demostraron la existencia de fragilidad cromosámica en linfocitos de estos pacientes (4). En 1971, este mismo grupo describió que los cambios cromosómicos constituyen un hallazgo consistente y están presentes cuando comienza a aparecer la falla en la médula (5).

La alteración de la transformación de fibroblastos por el virus oncogénico SV 40 , manifestada por roturas cromosómicas espontáneas en cultivos de tejidos de estos pacientes (6), es de interés, ya que sujetos con A.F. tienen un riesgo aumentado de desarrollar leucemia $(3.3 \%)(3,7--9)$. La alteración en la transformación de fibroblastos también se ha descrito en los padres (8). Los hombres heterocigotos (portadores) para la AF tendrian también un riesgo mayor que la población general (3-4 veces) para desarroltar tumores malignos (10). La presencia de malformaciones, pancitopenia, neutropenia y leucemia en algunos parientes aparentemente sanos se ha interpretado como manifestaciones de heterocigocidad (11). Estudios recientes demuestran la factibilidad de realizar diagnóstico prenatal para esta afección, utilizando un carcinógeno (diepoxibutano (DEB)), que induce roturas cromosómicas. Esta técnica permitiria, además, detectar los heterocigotos $(12,13)$. 
Sindrome de Trombocitopenia con Ausencia de Radios (T.A.R.)

Este síndrome fue descrito en 1956 y 1959 como una entidad distinta de la $\mathrm{AF}$, en pacientes con trombocitopenia, sin compromiso de la serie roja, de inicio en los primeros meses de vida (14. 16) En esta afección los cromosomas son normales (15). Diversas publicaciones han establecido su herencia autosómica recesiva y contribuido a delinear este síndrome $(2,16,17)$.

Las caracteristicas clínicas son trombocitopenia hipomegacariocitica congénita, reacciones leucemoides frecuentes (habría sólo un paciente con leucemia) y/o eosinofilia en los niños, anemia desproporcionada al sangramiento; ausencia o hipoplasia del radio, habitualmente bilateral, frecuentemente asociada con hipoplasia o ausencia del cúbito y defectos en las manos, pero siempre con pulgares presentes. También hat sido descritas alteraciones en las extremidades inferiores; cardiopatía congénita, comúnmente tetralogía de
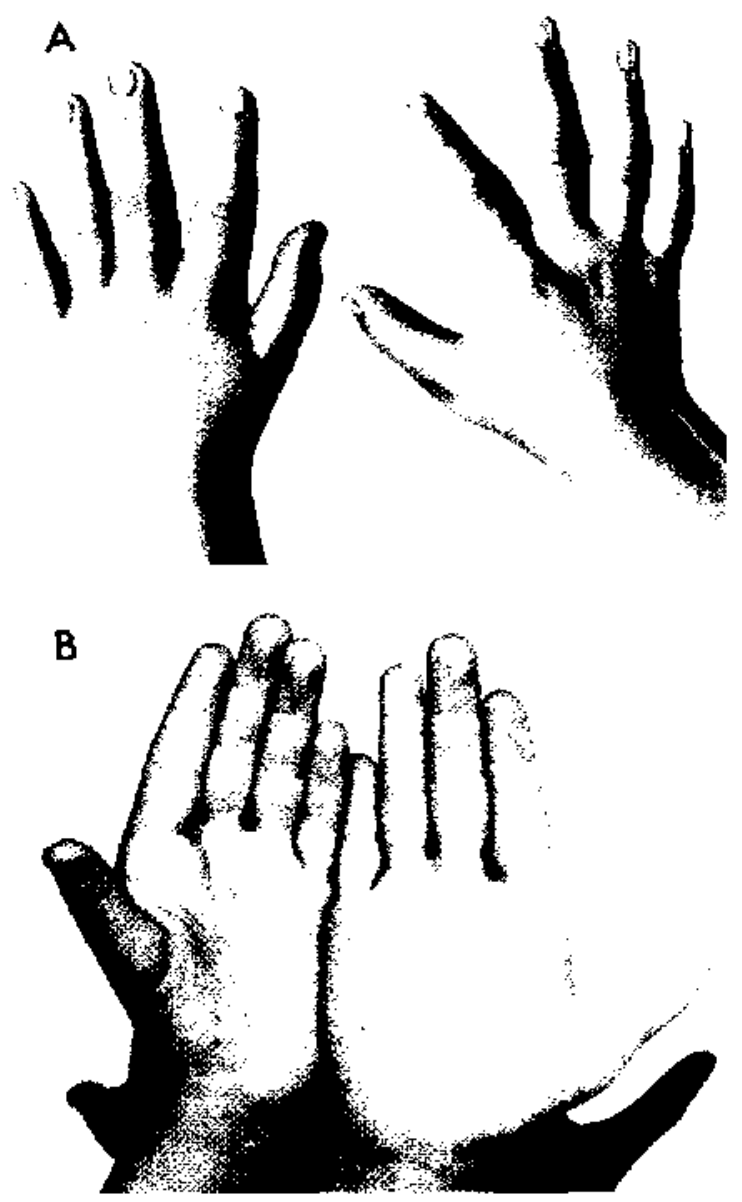

CASO I ( $A-B)$
Fallot, $y$ otras multiples malformaciones menos frecuentes (2). Cerca de un $40 \%$ de estos pacientes fallece en la infancia, generalmente a consecuencia de hemorragias. A pesar de la respuesta inconsistente a los corticoides, es importante su tratamiento, ya que el trastorno hematológico mejora al avanzar la edad $(2,16)$.

\section{Síndrome de Aase}

En 1969, Aase y Smith describieron un nuevo sindrome en 2 hermanos con anemia hipoplasica y pulgares trifalángicos (18). Otras publicaciones han contribuido a su delineación $(19,20)$. Sus principales características son: anemia hipoplásica, similar a la de Black-Diamond, de inicio temprano; ausencia o disminución significativa de leveocitos o plaquetas, y pulgares trifalángicos, ubicados en el mismo plano que los otros dedos. Si bien hay algunos pacientes descritos con ciertas características presentes en la $\mathrm{AF}(19,20)$, en el $\mathrm{S}$. de Aase no hay roturas cromosómicas $y$ existe una buena
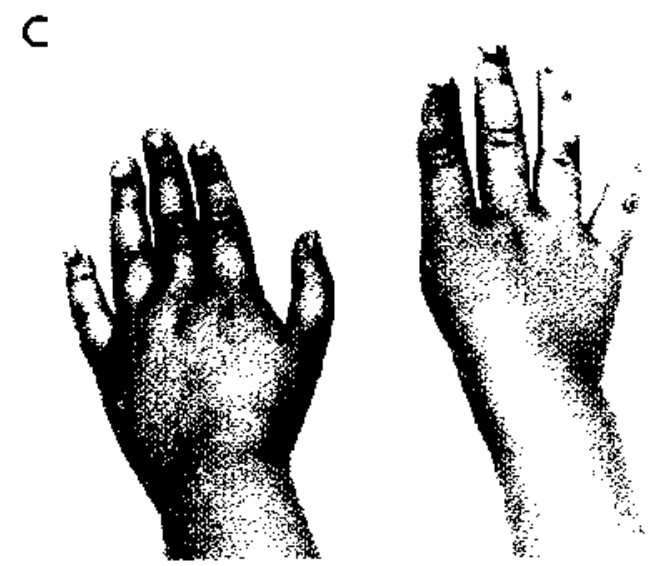

D

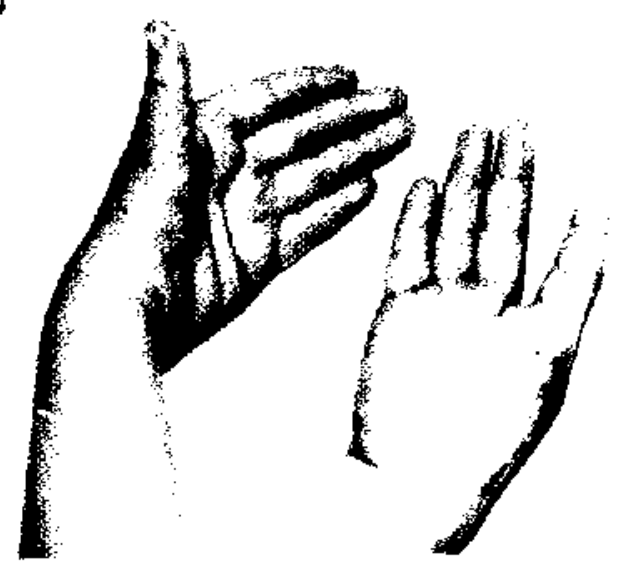

CASO 2 (C-D)

Figura 1 
respuesta de la anemia al tratamiento con corticoides (17).

El tipo de herencia aún no ha sido claramente definido. Se han sugerido diversos patrones hereditarios $(18,19,20)$. Su descripción inicial solamente en hombres, con posibles manifestaciones de heterocigocidad en una portadora, sugirió una herencia recesiva ligada al sexo (2). Sin embargo, la descripción de dos mujeres afectadas $(21,22)$ hace que esté considerada como afección recesiva en el catálogo de McKusick (20560) (23).

\section{CASOS CLINICOS}

\section{Caso 1 :}

Paciente referido para estudio genético a los 9 años 9 meses. Segundo hijo de padres aparentemente sanos, no consanguíneos. Producto de un embarazo normal, salvo el antecedente de retraso del crecimiento intrauterino. Al nacer se diagnosticó un niño PEG (P: $2400 \mathrm{gr}$ - 40 semanas) con polidactilia preaxial, operada en el período de RN y facie especial, planteándose la posibilidad de un cuadro genético. El único problema en su niñez. fue retraso del crecimiento atribuido a su problema genético. El hallazgo de trombocitopenia recibió mayor atención sólo a los 9 años 9 meses, cuando a raiz de un sarampión, recibió inyecciones seguidas de hemorragias locales, epistaxis y úlceras labiales a repetición. El hemograma reveló pancitopenia, por lo que fue referido a nuestra unidad para estudio de un posible Síndrome de Falconi.

El examen clínico demostró retraso del crecimiento (entre percentiles 3 y 10); circunferencia craneana entre p. 10 y 25 ; facie especial dada por epicanto, tendencia al hipotelorismo (distancia entre cantos internos $<3 \%$, cantos externos $25 \% \mathrm{e}$ interpupilar 3-25\%) y boca pequeria; mala implantación de pulgares, vestigio de polidactilia preaxial proximal operada (Fig. 1); leve mesobraquidactilia de meñiques; pies pequefios $(<3 \%)$; ligeta asimetría corporal, y dermatoglifos caracterizados por alto porcentaje de círculos, recuento total de líneas digitales alto (202), trirradios axiales intermedios; alteración del surco del pulgar y tendencia a surco simiano I a izquierda.

La historia familiar reveló el antecedente de una hermana menor con caracteristicas similares (Caso 2).

\section{Caso 2:}

Paciente de sexo femenino de 5 años 10 meses de edad, con boca muy pequeña, manchas pigmentarias en el tronco, ausencia del pulgar derecho con zonas tenares de escaso desarrollo. Un pulgar rudimentario en la mano derecha había sido operado en PRN (Fig. 1). En los dermatoglifos destacaba asimetría de dibujos digitales con un recuento de líneas (RTLD 87), presillas radiales en ambos indices $y$ en el dedo medio izquierdo, trirradios axiales intermedio a izquierda y distal a derecha, líneas principales transversales y alteración de los surcos de flexión palmares.

El estudio hematológico reveló una pancitopenia aún más severa que en su hermano.

\section{Análisis Cromosómico:}

El análisis cromosómico de los hermanos confirmó el diagnóstico de $\mathrm{AF}$ al encontrarse numerosas anomalías cromosómicas (Tabla 1 y Fig. 2).

Tabla 1

Analisis Cromosómico

\begin{tabular}{|c|c|c|c|c|c|c|}
\hline & Caso 1 & Caso 2 & Padre & Madre & $\begin{array}{l}\text { Controles } \\
\bar{x}(\mathrm{~N}=4)\end{array}$ & Caso 4 \\
\hline $\begin{array}{l}\text { Porcentajes de Mitosis con } \\
\text { Anomalías Cromosómicas }\end{array}$ & 30.21 & 60.29 & 3.8 & 8.2 & 2.75 & 9.85 \\
\hline Número Mitosis Antalizadas & 96 & 103 & 53 & 76 & 400 & 71 \\
\hline GAPS & 13 & 26 & - & 2 & 10 & 3 \\
\hline Fracturas de Cromátides & 4 & 9 & - & - & 1 & 4 \\
\hline Fragmentos & 4 & 17 & 2 & 4 & - & \\
\hline Anillos & 2 & 2 & - & .. & - & \\
\hline Dicéntricos & 4 & 5 & - & - & - & \\
\hline Intercambios de Cromátides & 2 & 4 & - & - & - & \\
\hline
\end{tabular}

- Se analizaron 100 mitosis en cada control. 


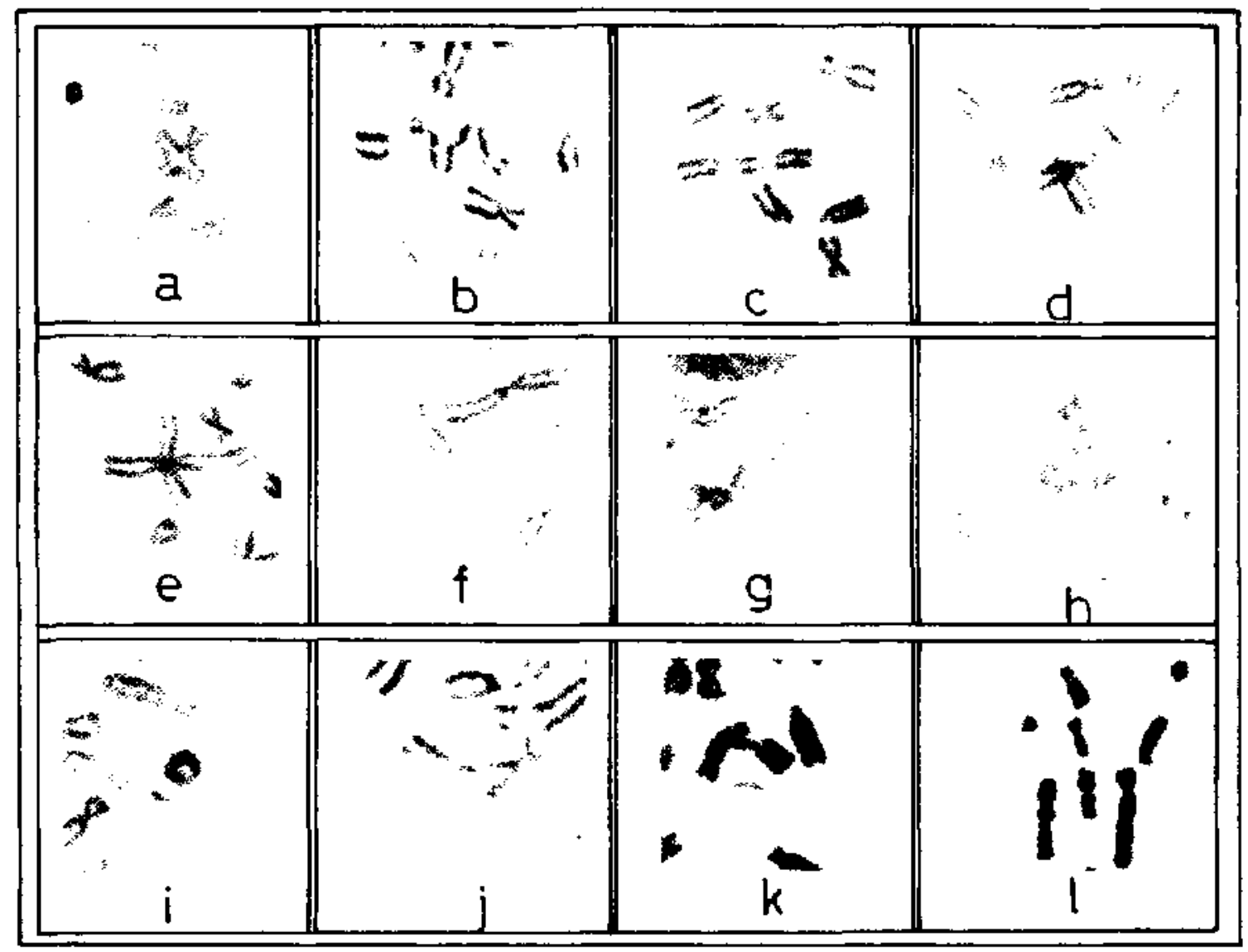

Fig. 2 Alteraciones cromosomicas casos: 1 (A-G), 2 (H-K). 4 (L).

\section{Estudio Familiar:}

La busqueda dirigida de antecedentes familiares demostró una historia de hemorragias severas postoperatorias en la madre, la que recientemente había sido operada por un cáncer cérvico-uterino. Al examen físico, ambos padres presentaban una talla sobre el percentil 90 y tenían 2 presillas radiales en mano izquierda (índice y medio en la madre e indice y anular en el padre), además de líneas principales transversales y trirradios axiales intermedios. La facie del padre era llamativa por hipotelorismo (ip $50 \mathrm{~mm}$ ) y boca pequeña $(45 \mathrm{~mm})$. La distancia interpupilar en la madre era de $63 \mathrm{~mm}$ y la comisura bucal media $50 \mathrm{~mm}$. El estudio cromosómico en el padre reveló la presercia de un fragmento extra en 2 de las 53 mitosis analizadas (3.8\%) y un cromosoma 22 con satélites muy marcados. Este marcador estaba presente también en su hija (Caso 2). En 76 mitosis analizadas en la madre se encontraron 2 mitosis con gaps y 4 mitosis con fragmentos (Tabla 1).
Caso 3: (Obs. No 315253 ) H.S. del R.)

R.N., de sexo masculino, hijo de padres aparentemente sanos (padre, 28 años, madre 23), no consanguíneos, producto de un segundo embarazo, con un hermano sano. El embarazo cursó con síntornas de aborto en el primer trimestre; prediabetes; polihidroamnios, comprobado por ecografías al 60,80 , y 90 mes sin detectar malformaciones congénitas; herpes en el 20 trimestre, tratado con prednisona y sindrome hipertensivo en el último mes. El 20.1.82, debido a rotura prematura de membrana y sufrimiento fetal, se practica una cesárea dando nacimínto a un niño de pretérmino (33 semanas) AEG (peso $2.000 \mathrm{gr}$ ), con asfixia neonatal severa (Apgar 2, 5 y 7) y múltiples malformaciones congénitas.

El examen clínico reveló macrocefalia, (cc $34.4 \mathrm{cms}$ ), facie con rasgos finos y boca chica, latidos cardíacos subxifoídeos con tonos muy timbrados (ectopia cordis), pene pequeño, edematoso, con testículos en escroto, marcada limitación de la abducción de cadera, talones prominentes. leve 
sindactilia cutánea entre los $2^{\circ}$ y 3 .er ortejos y malformaciones de extremidades superiores. Estas consistían en leve acoltamiento de húmeros, marcado acortamiento del antebrazo derecho con ausencia del radio, discreto acortamiento de antebrazo izquierdo por hipoplasia de cúbito y radio, manos en flexión palmar y aducción forzada (Fig. 3). Lá implantación de pulgares era algo distal, adoptando posición transversa, existiendo además una polidactilia postaxial de tipo $B$ bilateral. Los pliegues de flexión digitales estaban ausentes, los pliegues de flexión palmares alterados y los dermatoglifos presentaban variaciones secundarias a las alteraciones de manos descritas.

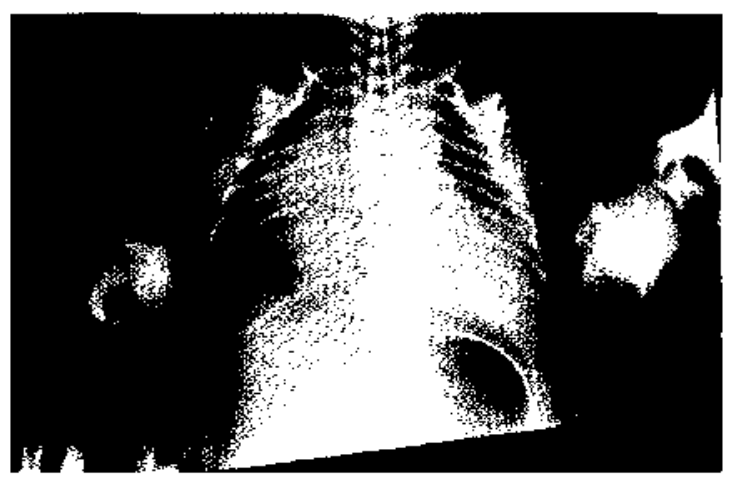

Caso 3. Se observa ectopia cordis, leve hipoplasia de húmeros, ausencia de radio a derecha con hipoplasia de cúbito y radio a izquierda.

Figura 3

El niño evolucionó con crisis de apnea $y$ cianosis que requirieron respirador y con tendencia al sangramiento leve, pero persistente. Los recuentos de plaquetas fueron 48.000 y 16.225 , subiendo a 208.000 después de una transfusión de concentrados plaquetarios. Con ésta disminuyó la cuantía del sangramiento. Sin embargo, un control ulterior demostró 62.000. Un mielograma reveló ausencia de megacariocitos. A pesar de las medidas terapéuticas, se mantuvo con acidosis metabólica y persistencia del problema respiratorio, falleciendo por paro cardiaco al tercer día de vida. No se realizó autopsia ni estudio cromosómico. E1 diagnóstico de la sala fue $S$. de Trombocitopenia con Ausencia de Radios.

\section{Caso 4:}

Lactante de un mes y 10 días (F.N. 28.1.82) referido para estudio por malformación congênita de ambas extremidades superiores, acomparada de otras alteraciones. Producto de un primer embarazo, hijo de padres sanos, consanguineos (padre, 27 años; madre, 33), cuyos únicos antecedentes fami- liares se observan en la figura 4. El embarazo cursó sin complicaciones hasta el 70 mes en que se notó detención del crecimiento uterino. En el segundo trimestre se había realizado amnioscentesis por los antecedentes de consanguinidad, informándose un cariotipo normal.
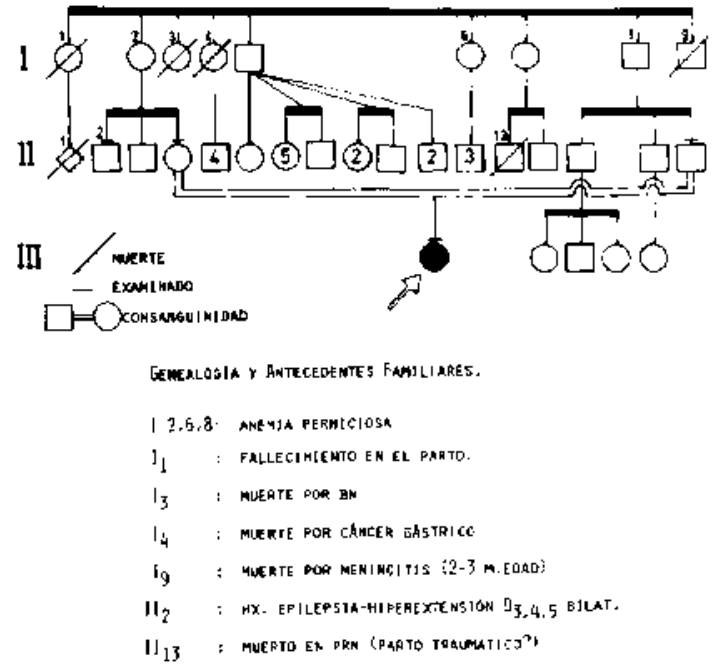

Figura 4

El parto se produjo a las 38 semanas de gestación con un peso de nacimiento de 2.300 gr. y talla de $43.5 \mathrm{cms}$. Al examen destacaron malformaciones de extremidades superiores y cardiopatía congénita. Un hemograma hecho al tercer dia demostró trombocitopenia. Un recuento a los 5 días demostró 25.000 plaquetas. Los 'hechos positivos que observamos al examen clínico fueron: cardiopatía congénita (observación ClA o EP moderada), pequeña hernia umbilical, leve deformidad de pies con ortejos mayores grandes $y$ aumento de separación entre 1 .er y 20 ortejos. En el brazo derecho se observaba una mancha café con leche de $1 \times 1.5 \mathrm{cms}$. Había acortamiento importante de ambos antebrazos por ausencia de radios, con malposición de manos. En éstas se observaba la presencia de sólo 4 dedos (Fig. 5). Sin embargo, el primero a derecha simulaba un pulgar rudimentario. A izquierda destacaba flexión del índice. Los pliegues de flexión palmares y digjtales estaban alterados en ambas manos. El estudio citogenético reveló fragilidad cromosómica en un 10\% de las mitosis analizadas (Fig. 1 y Tabla 1). Hasta la actualidad no ha vuelto a presentar manifestaciones hematológicas. El recuento plaquetario al mes y 20 dias fue de 250.000 . Un mielograma realizado a los 4 meses, reveló megacariocitos en cantidad normal, pero con aumento de megacariocitos jóvenes jnmaduros. La biopsia de médula fue normal. 
Desde el punto de vista clínico, lo más llamativo es un evidente retraso del crecimiento (1 mes
18 días: P 2.620 grs.; T. 47 cms.; 4 meses: P. $3.520 \mathrm{grs}$. T. $51.5 \mathrm{cms}$.).
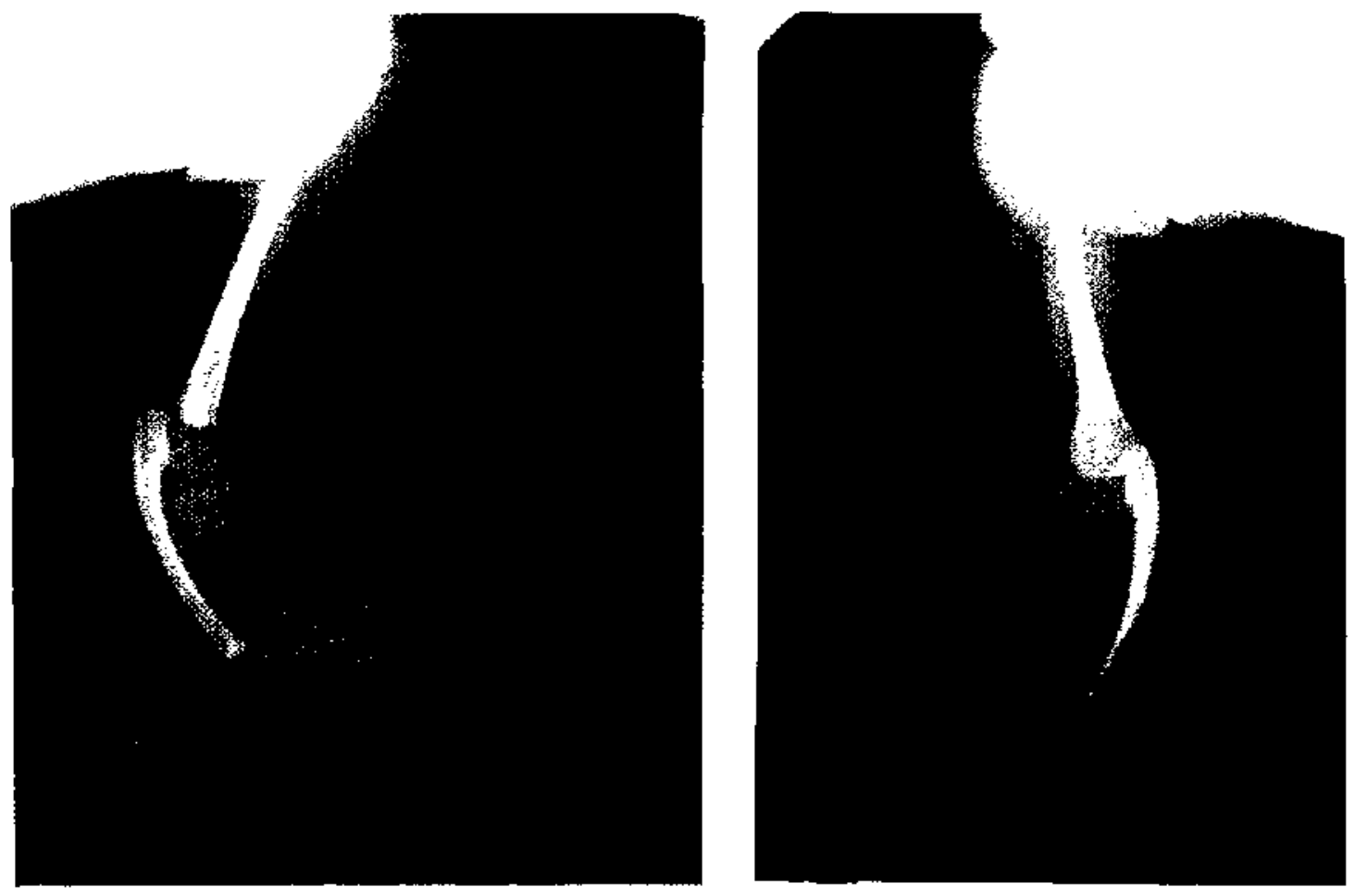

Caso 4. Se observa ausençia de radios y malposición de manos que sólo presenta 4 dedos.

Figura 5

\section{DISCUSION}

Si bien estos síndromes son afecciones poco frecuentes, es importante el diagnóstico diferencial entre ellos por su implicancia pronóstica y de consejo genético (Tabla 2). Es fácil establecer el diagnóstico si existe un gran número de manifestaciones claramente definibles o si hay otros miembros de la familia afectados. Sin embargo, pacientes con alteraciones minimas o parciales o con características comunes a 2 o 3 de estos síndromes de disfunción medular y defectos radiales, pueden constituir casos de diagnóstico muy difícil.

Los casos 1 y 2 no ofrecieron duda diagnóstica, por cuanto eran hermanos, presentaban pancitopenia de comienzo característico, malformaciones esqueléticas y otras manifestaciones fenotípicas evidentes. Los exámenes de laboratorio, como hemoglobina fetal aumentada, alteraciones típicas en la médula y abundantes manifestaciones de fragilidad cromosómica, fueron concordantes.

Dado que ambos padres son heterocigotos obligados, se investigó en èllos la presencia de: antecedentes de patologias que pudieran tener relacion con este sínởrome; alteraciones al examen fisico y búsqueda de anormalidades cromosómicas. La historia de hemorragias postoperatorias severas y de cancer cérvico-uterino en la madre y la facie especial en el padre, si bien pudieran ser coincidentes, podrían ser manifestaciones de cierta expresión del gene al igual que la presencia de un bajo porcentaje de fragmentos (24).

De Grouchy, en 1972 (25), describió manifestaciones de inestabilidad cromosómica en linfocitos de sangre periférica de portadores. Estos hallazgos no han sido confirmados.

La reciente descripción de un método para detectar heterocigotos a través del estudio cromosómico con $\operatorname{DEB}(12,13)$, permitirá, en el futuro, una mejor delineación de posibles manifestaciones fenotípicas, vigilancia médica y consejo genético en estos sujetos.

En el caso 3, el diagnóstico de TAR se sustenta en la trombocitopenia presente al nacer, la presencia de pulgares, la alteración medular compatible y mortalidad precoz. Esta no permitió hacer estudio cromosómico. 
Tabla 2

Diagnóstico Diferencial de Síndromes de Defectos Radiales con Disfunción Medular

\section{Sindrome}

Elementos

Diferenciales

Anemia de Fanconi

S. TAR

S. AASE

A)

GENERALES

Frecuencia

Sexo (ơ : $\varsubsetneqq)$

Herencia

Consanguinidad

Heterocigoto

Diag. Prenatal Específico

Antecedentes de Cancer

o Leucemia Familiar

Edad aparición de las

alteraciones hema1ológicas

\section{$1 / 350.000 \mathrm{RN}$}

2:1

Autosómica Recesiva

Frecuente (27/111)

Detectable

Cromosómico

Riesgo $\uparrow$ ( 3.4 veces)

$17 \mathrm{~m}-22$ años

$\bar{x} \underbrace{0.6 \text { años }}$
Menos de 100 casos desetitos

$1 \cdot 2$

Autosómica Recesiva

Sólo rasgos

Posible

RN - lactantes

RN
Menos de 10-12 casos descritos

$$
3: 1
$$

No precisada

(posiblemente a.r.)

Sólo rasgos

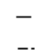

Pulgar

Radio

Otras Alt. Esqueléti-

cas (húmero, cúbito,

extr. inf.)

Hombros estrechos

Otras malformac. cong.:

- Renales

- Cardiacas

Hiperpigmentactón de piel

Alt. Hematológicas

- Sangramiento

- Infecciones recurrentes

Retraso del Crec.

Retraso Mental

Microcefalia

Facie Especial

(ojos y boca pequeña)

Hipogenitalismo
Hipoplasia o Aplasia (78\%

Hipoplasia o Aplasia

Frecuentes

Ocasional

Frecuente

( $\uparrow$ con cdad)

desde $\operatorname{tos} 5-10$ affos desde RN (PEG)

$(50-60 \%)$

$20 \%$

$+(43 \%)$

Frecuente

$$
+(44 \%)
$$

Hipoplasia o Normal Siempre presentes

Hipoplasia o Aplasia

Bilateral

Frecuentes

$+135 \%$

Ocasional

Frecuentes ( $\left.33{ }^{\circ} \%\right)$

recuentes

Rara

$\begin{array}{rc}+ & + \\ - & -\end{array}$

Raro

Presente
Aumentada

Pancitopenia

$\begin{array}{ll}\text { Normal } & \text { Aumentada } \\ \text { Trombocitopenia } & \text { Anemia Hipoplásica } \\ \text { R. Leucemoide (62\%) } & \text { Congénita } \\ \text { Eosinofilia (53\%) } & \text { Leucopenia variable }\end{array}$

Puede regresar espontáneamente

Transfusiones

- Esteroidal a per-

- Mortalidad manencia (mala respuesta)

- Esplenectomía on algunos casos

Elevada

$1: 30$

Corticoides (regular respuesta)

$-40 \%$ en infancia debida a hemorragias

- baja en el mayor

Riesgo a desarrollar leucenia
Baja

Puede regresar

\section{Corticoides \\ (buena respuesta)}

1 caso descrito. 
EI caso 4 ilustra las dificultades diagnósticas en algunos pacientes. La presencia de cardiopatía con malformaciones de manos sugirió, inicialmente, a uno de los especialistas un Síndrome de Holt-Oram. En esta afección puede haber ausencia o hipoplasia de pulgares, aunque generalmente son trifalángicos y no presenta alteraciones hematológicas. La presencia de trombocitopenia al nacer con ausencia bilateral de radios, nos hizo sugerir un $S$. de TAR, a pesar de la aparente ausencia de pulgares. Sin embargo, la existencia de fragilidad cromosómica, el retraso acentuado del crecimiento, la mancha café con leche y el antecedente de consanguinidad, frecuente en AF y no en TAR, nos hizo plantear finalmente un diagnóstico de Anemia de Fanconi. Este diagnóstico, desgraciadamente, implicaría un peor pronóstico, en una lactante en que la trombocitopenia inicial ha mejorado espontáneamente.

Las alteraciones cromosómicas, espontáneas o inducidas, previo a la aparición de las alteraciones hematológicas, son de gran ayuda en el diagnóstico diferencial de estos cuadros, especialmente en aquelios del inicio extraordinariamente precoz como seria este último caso.

El diagnóstico prenatal de estas afecciones se basa en la pesquisa de malformaciones esqueléticas a través de ecografía, radiografias o fetoscopía. La inducción de fragilidad ел cultivos cromosómicos en líquido amniótico, permitiendo el diagnóstico prenatal específico de la Anemia de Fanconi, significa un avance notable en el manejo y prevención de la mas frecuente de las afecciones discutidas.

\section{RESUMEN}

Se describen 2 hermanos con Pancitopenia de Fanconi (A.F.) típica; un recién nacido con el Sindrome de Trombocitopenia con Ausencia de Radios (T.A.R.), que murió a las pocas horas de nacer, $y$ una niña con radios y pulgares ausentes $y$ trombocitopenia transitoria en el periodo de tecién nacido. El hallazgo en esta última paciente de gaps y fracturas en el $10 \%$ de las mitosis analizadas, establecería el diagnóstico extraordinariamente precoz de A.F. Se revisan los conocimientos actuales y el diagnóstico diferencial de los 3 síndromes de hipoplasia medual asociada a malformaciones de las extremidades como son las A.F., T.A.R. y S. de Aase. Aunque estas enfermedades son poco frecuentes, se enfatiza la importancia del diagnóstico diferencial de estos síndromes.

\section{AGRADECIMIENTOS}

Agradecemos a los Dres. T. Walter, J. Torres P. y J. Wilson, que nos refirieron los pacientes. A los
Dres. T. Waiter, H. Taboada y A. Daiber, por los estudios hematológicos realizados y a la Sra. Viola Lyon, por su excelente labor secretarial.

\section{REFERENCLAS}

1 Fanconi, G.: Familiäre Infantile Perniciosa Artigeanämie. J.B. Kinderheilk 117: 257, 1927.

2 Smith, D.W.: Recognizable pattems of human malformation. W.B. Saunders Company, Philadelphia, 2nd. Edition, 1976.

3 Beard. M.E.J; Young, D.E.; Baterman, C.I.I.; McCarthy. G.T.; Smith, M.E.; Sinclair, L.; Franklin, A.W.: Bodley-Scott, R. Fanconi's Anaemia. Quarterly Journal of Medicine, New Series, XLJI, No 166, 403, April, 1973.

4 Schroeder, T.M.; Anschutz, F.; Knopp, A.: Spontane chromosome aberrationen Bei farriliare Panmyelopathie. Humangenetik l: 194, 1964.

5 Schroeder, Y.M.; Kurth, R.: Spontaneous cliromosomal breakage and high incidence of leukemia in inherited disease. Blood 87: 96, 1971.

6 Todaro, G.J.: Green, H.: Swift, M.R.: Suceptibility of human diploid fibroblast strains to transformation by SV 40 virus. Science 153:1252, 1966.

7 Garriga. S.; Crosby, W.H.: Incidence of leukemia in families of patients with hypoplasia of marrow. Blood 14: $1008,1959$.

- Swift, M.R.r Hirschhorn, K.: Fanconi's Anaemia in the genetics of neoplasia. Nature 230:370, 1971.

9 Swift, MR.; Zimmermon, D.; McDonough, E.R.: Squamous cell carcinoma in Fanconi's Anemia. J. Amcr. Med. Ass. 216: 325, 1971.

10 Dosik, M.: Leukemia in Fanconits Anemia. Cytogenetic and tumor virus suceptibility studies. Blood 36 : $341,1970$.

1 I Swift, M.R.; Cohen, J,; Pinlchham, R.: Maximum likelihood method for estimating the disease predisposition of heterozygotes. Am. J. Hum. Genet. 26: 304, 1974.

12 Voss, R.: Kohn, G.; Shaman, M.; Benzur, Z.; Armon, J.; Ornoy, A,; Yoffe, H,; Golbus, M.; Auerbach, A,D.: Prenatal diagnosis of Fanconi Anemia. Clinical Genetics, 20: 185, 1981.

13 Auerbach, A.D.; Adler, B.: Prenatal and post-natal diagnosis and carrier detection of Fanconi Anemia by a cytogenetic method. Pediatrics 67; 128, 1981.

14 Gross, H.: Kongenitale hypoplastische thrombopenie mit radiusaplasie. Ein sydrom multipler abartunger. N. Oest. Z. Kinderheilkd 1: 574, 1956.

15 Shaw, $S$; Oliver, R.A,M.: Congenital hypoplastic thrombocytopenia with skeletal deformities in siblings. Blood 14: 374, 1959.

16 Hall, J.G.: Thrombocy topenia with Absent Radius (TAR) Medicine 48: 411, 1969.

13 Temtamy, S.: McKusick, $V_{\text {:: }}$ Tehe genetics of hand malformation. BD.: OAS, Vol, XIV, No 3. The National Foundation March of Dimes. Alan R. Liss. lnc, New York, 1978.

18 Aase, J.M.; Smith, D.W.; Congenital anemia and triphalangeal thumbs-A new Syndrome. J. Pedjatr. 74: 471,1969

19 Murphy, S.; Lubin, B.: Trhiphalangeal thumbs and congenial erythroid hypoplasia. Report of a case with unsual features. J. Pediatr, 81: 987, 1972.

20 Jones. B.; Thompson, H.: Triphalangeal thumbs associated with hypoplasia anemia. Pediatrics $52: 609$, 1973. 
21 Van Wellsiamon, M.: Van de Kamp, J.J.P.; Koning, $J .:$ A female patient with "Aase Syndrome". J. Pediatr. 91: $753,1977$.

22 Harvey, D.R.: Congenital hypoplastic anemia. Proc. R. Soc. Med. 59: 490, 1966.

23 McKusick, V.A.: Mendelian inherjtance in man. Catalogs of autosomal dominant, autosomal dominant, autosomal recessive, and $\mathrm{X}$-linked phenotypes. Fifth Edition. Johns Hopkins University Press. Baltimore,
1978.

24 Lacassie, Y.; Curotto, B.; Ojeda, E.: Seebach, Ch.: Anemia de Fanconi: Búsqueda de anormalidades en heterocigotos obligados. XVI Reunión Anual SLAIP, Chile. 1978 (Pediat. Res. 14(1): 74, 1980 ).

is De Grouchy, J; De Nova, C.; Marchand, J.C.; Feingold, $f_{\text {. }}$ Turleau, $E$.: Cy togenetic and Biochemical Studjes of Eight Cases of Fanconi's Anemia. Ann. Genet. 15: 29, 1972. 